\title{
KARAKTERISTIK DAN ASPEK BIOLOGI Scaphopoda (MOLUSKA)
}

\author{
Oleh \\ Putri Sapira Ibrahim ${ }^{1)}$
}

\begin{abstract}
CHARACTERISTICS AND BIOLOGICAL ASPECTS OF Scaphopoda (MOLLUSCS). Scaphopoda are bilaterally symmetrical marine molluscs, commonly known as the "tusk shells" because their shells are conical. There are approximately 900 species of Scaphopoda, found in soft silty marine sediments, which they burrow in search of food. Scaphopoda feeds on microorganisms, their diet dominated by foraminiferans. Hermaphroditic scaphopoda has been reported but rare. The biodiversity of Scaphopoda had been underestimated because the taxonomic and biological aspects of scaphopoda have not been well studied. Classification, morphology, reproduction, behavior, habitat, and distribution of Scaphopoda are discussed in this paper.
\end{abstract}

Keywords: Scaphopoda, Elephant tusk shells, Molluscs, Life history.

\section{PENDAHULUAN}

Scaphopoda merupakan salah satu kelas dalam filum Moluska. Kelas Scaphopoda merupakan kelas kecil moluska laut dan jarang ditemukan (Romimoharto \& Juwana, 2007), dikenal dengan nama kerang gigi atau gading (Kozloff, 1996). Anggota kelas ini yang dijumpai di laut di antaranya yaitu Dentalium sp. Spesies ini disebut Dentalium karena bentuk cangkangnya menyerupai gigi (dentis).

Scaphopoda adalah moluska laut yang bentuknya simetris bilateral, dengan cangkang eksternal berkapur yang terbuka di kedua ujungnya dan sedikit melengkung. Scaphopoda memiliki ukuran dan bentuk yang beragam. Antara ordo satu dan ordo yang lainnya dapat memiliki ukuran tubuh dan cangkang yang berbeda. Anggota dari ordo Dentaliida biasanya memiliki ukuran yang lebih besar dibandingkan ordo
Gadilida (Kozloff, 1996). Kelompok dentalid juga memiliki cangkang yang bergaris-garis dan lebih kasar dibandingkan kelompok Scaphopoda lainnya.

Scaphopoda hidup di perairan laut, sekitar 500 spesies ditemukan dari sedimen laut baik di perairan dangkal maupun perairan dalam di seluruh lautan dunia (Scarabino, 1994). Menurut Brusca dan Brusca (2003), saat ini sudah tercatat sekitar 900 spesies Scaphopoda. Contoh dari Scaphopoda adalah Dentalium vulgare. Hewan ini hidup di laut atau di pantai yang berlumpur, bercangkang tajam, berbentuk taring/terompet dengan kedua ujungnya yang terbuka karena disesuaikan dengan tempat hidupnya.

Sebagian besar Scaphopoda tidak dapat dikoleksi dengan mudah karena hidup pada laut dalam dan kelimpahannya selalu terbatas sehingga informasi mengenai biologi dan ekologi kelas ini masih belum

\footnotetext{
1) Loka Konservasi Biota Laut Bitung, Sulawesi Utara - LIPI
} 
banyak diketahui, sehingga diperlukan lebih banyak upaya untuk mengungkap keanekaragamannya. Tulisan ini merupakan suatu tinjauan mengenai Kelas Scaphopoda mencakup informasi klasifikasi, morfologi, anatomi, reproduksi, habitat dan distribusi yang dirangkum dari berbagai sumber. Melalui ulasan ini, diharapkan dapat menambah informasi dan pengetahuan tentang Kelas Scaphopoda.

\section{KARAKTERISTIK DAN ASPEK BIOLOGI SCAPHOPODA}

\section{a. Klasifikasi Scaphopoda}

Steiner \& Kabat (2004) menerbitkan katalog kelompok nama spesies dari Scaphopoda baru dan fosil Scaphopoda, sebanyak 517 spesies yang mewakili 2 ordo (Dentaliida dan Gadilida) dan 45 genus, terdaftar sebagai valid taksa baru di laut dunia.

Ordo Dentaliida merupakan Scaphopoda dengan kelenjar midgut (usus tengah) berpasangan dan dua pasang otot dorsoventral yang tidak sepenuhnya terpisah. Ordo ini terdiri dari 8 famili yaitu:

- Dentaliidae, 14 genus

- Fustiariidae, 1 genus

- Rhabdidae, 1 genus

- Laevidentaliidae, 1 genus

- Gadilinidae, 2 genus

- Omniglyptidae, 1 genus

- Anulidentaliidae, 3 genus

- Calliodentaliidae, 1 genus

Gadilida merupakan Scaphopoda dengan kelenjar midgut tidak berpasangan (kiri) dan sepasang otot dorsoventral. Ordo ini terdiri dari 2 subordo yaitu:

1. Subordo Entalimorpha

- Famili Entalinidae, 9 genus

2. Gadilimorpha

- Famili Gadilidae, 8 genus

- Famili Pulsellidae, 3 genus
- Famili Wemersoniellidae, 2 genus

(Steiner, 1992)

Berikut adalah klasifikasi dari genus Dentalium:

$\begin{array}{ll}\text { Kingdom } & : \text { Animalia } \\ \text { Filum } & \text { : Mollusca } \\ \text { Kelas } & : \text { Scaphopoda } \\ \text { Ordo } & : \text { Dentaliida } \\ \text { Famili } & \text { : Dentaliidae } \\ \text { Genus } & \text { : Dentalium }\end{array}$

(Steiner \& Dreyer, 2002)

\section{b. Morfologi dan Anatomi}

Scaphopoda memiliki tubuh yang berukuran kecil dan ramping. Scaphopoda dikenal karena bentuknya yang menyerupai gading (Reynolds, 2002). Cangkangnya meruncing dari ujung depan ke ujung belakang, karenanya disebut cangkang gading (tusk shell). Cangkangnya melengkung dan bagian dalamnya berongga. Kedua ujungnya terbuka, yang satu lebih besar dari pada yang lain (Romimoharto \& Juwana, 2007).

Cangkang memiliki pahatan utama yang memanjang, terdiri dari sekitar 10 tulang rusuk primer (kadang hingga 15) di bagian posterior. Pada cangkang antara tulang rusuk longitudinal primer, ada tulang rusuk sekunder dengan ketebalan hampir sama dengan tulang rusuk primer (Ozturk, 2011). Cangkang berukuran sekitar $80 \mathrm{~mm}$, berdinding tebal, permukaan halus, warna putih, lengkungan lentur dan bundar (Simone, 2009; Souza et al., 2013).

Kaki dan kepala Scaphopoda yang kecil atau berbentuk probosis tersembul pada aperture anterior yang lebih besar. Pada kepala terdapat mulut dan kaptakula, tetapi tidak ada mata dan tentakel sebagai alat indera. Kaptakula berbentuk filamen yang kontraktil, dan pada tiap ujungnya terdapat tontolan yang adesif. Bagian tubuh Scaphopoda disajikan pada Gambar 1. 


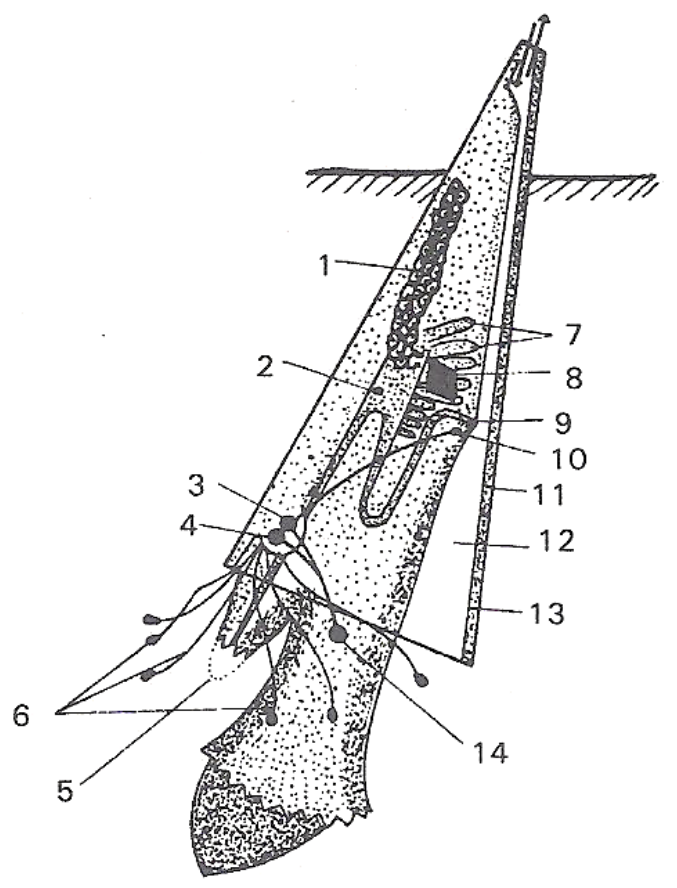

Struktur hewan memendam diri dalam pasir, kecuali ujungnya untuk keluar masuk arus air

1. Gonad

2. Perut

3. Ganglion pleural

4. Ganglion serebral

5. Mulut

6. Kaptakula

7. Kelenjar pencernaan

8. Ginjal

9. Anus

10. Ganglion viseral

11. Cangkang

12. Ruang mantel

13. Mantel

14. Ganglion pedal

Gambar 1. Anatomi Scaphopoda, Dentalium sp (Hegner, 1993).

\section{c. Reproduksi}

Scaphopoda memiliki bentuk gonad agak elips, panjang gonad sekitar 1/4 panjang cangkang, 4 kali lebih panjang dari lebar dan berwarna krem pucat. Memiliki gonad tunggal yang umumnya berada di bagian posterior tubuh. Ujung anterior gonad terhubung ke gonoduct, berdinding sangat tipis dan transparan (Simone, 2009; Grzimek et al., 2003).

Scaphopoda bersifat gonokoristik yaitu jenis kelamin terpisah antara jantan dan betina, dan bereproduksi secara seksual dengan cara mengeluarkan gamet ke air melalui nefridium. Telur dilepaskan secara terpisah ke dalam kolom air, telur bersifat planktonik. Sesudah stadium larva yang singkat, hewan-hewan muda akan berada di dasar laut. Scaphopoda memiliki tahap larva berenang bebas yang berkembang di dalam air dan pada akhirnya berubah menjadi bentuk tubuh Scaphopoda yang khas. Cangkang pertama yang disekresikan oleh Scaphopoda yaitu praetubulus larva, yang akan segera luruh dan ujung anterior akan tumbuh secara bertahap seiring dengan perpanjangan ukuran tubuh (Barnes, 1987; Encyclopedia, 2019; Grzimek et al., 2003). Informasi mengenai reproduksi ini dapat memperhitungkan potensi pemijahan dan sangat berperan dalam menentukan kelangsungan hidup (Ibrahim et al., 2016). Aspek biologi yang juga mencakup informasi reproduksi ini dapat menjadi indikator untuk dasar pengelolaan yang baik dari suatu organisme agar tetap lestari dan berkelanjutan (Ibrahim et al., 2017).

\section{d. Habitat}

Scaphopoda adalah organisme laut dalam yang masih berhasil bertahan dengan lebih dari 500 spesies yang ada (Scarabino, 1994; Steiner \& Linse, 2000; Reynolds \& Steiner, 2008). Semua Scaphopoda adalah mikrokarnivora bentik euhalin yang mendiami semua jenis lingkungan perairan dasar yang lunak (Palmer \& Steiner, 1998). Scaphopoda hidup dalam pasir atau lumpur, terpendam di bawah permukaan 
(Romimoharto \& Juwana, 2007). Scaphopoda tipe dentalium hidup di sedimen yang sedikit lebih kasar dengan campuran fraksi berpasir dan detritus cangkang seperti pada Gambar 2 (Kaim, 2012). Sedimen yang teroksigenasi dengan baik, berhubungan dengan keberadaan Scaphopoda. Diduga adanya lapisan sedimen tipis yang teroksigenasi menjadi tempat hidup moluska berukuran kecil (contohnya Scaphopoda) yang hidup di dasar laut (Kaim, 2012). Wignall (1990), menyebutkan bahwa kelimpahan Scaphopoda menurun drastis di daerah kaya organik, menunjukkan toleransi yang rendah terhadap penipisan oksigen. Beberapa Scaphopoda diketahui berhubungan dengan kebocoran metana (Goedert \& Squires, 1990).

\section{e. Distribusi}

Scaphopoda merupakan hewan bentik yang hidup sebagian membenamkan diri dalam substrat lunak, menghuni substrat batial dan abisal. Hampir $70 \%$ dari spesies yang diketahui ditemukan di bawah kedalaman $500 \mathrm{~m}$, hidup di bawah $3000 \mathrm{~m}$ juga memiliki persentase tinggi, bahkan mencapai kedalaman sekitar $7000 \mathrm{~m}$ (Scarabino, 1986; Poppe \& Goto, 1993; Palmer \& Steiner, 1998).

Kelas Scaphopoda dengan nama genus Dentalium elephantinum (Gambar 3) hanya ditemukan satu keping di Kabupaten Seram, Maluku, Indonesia (Surbakti \& Ririmasse, 2016). Sedangkan Dentalium elephantinum juga ditemukan di Desa Sako, Sumatera Selatan (Suriadi, 2018).

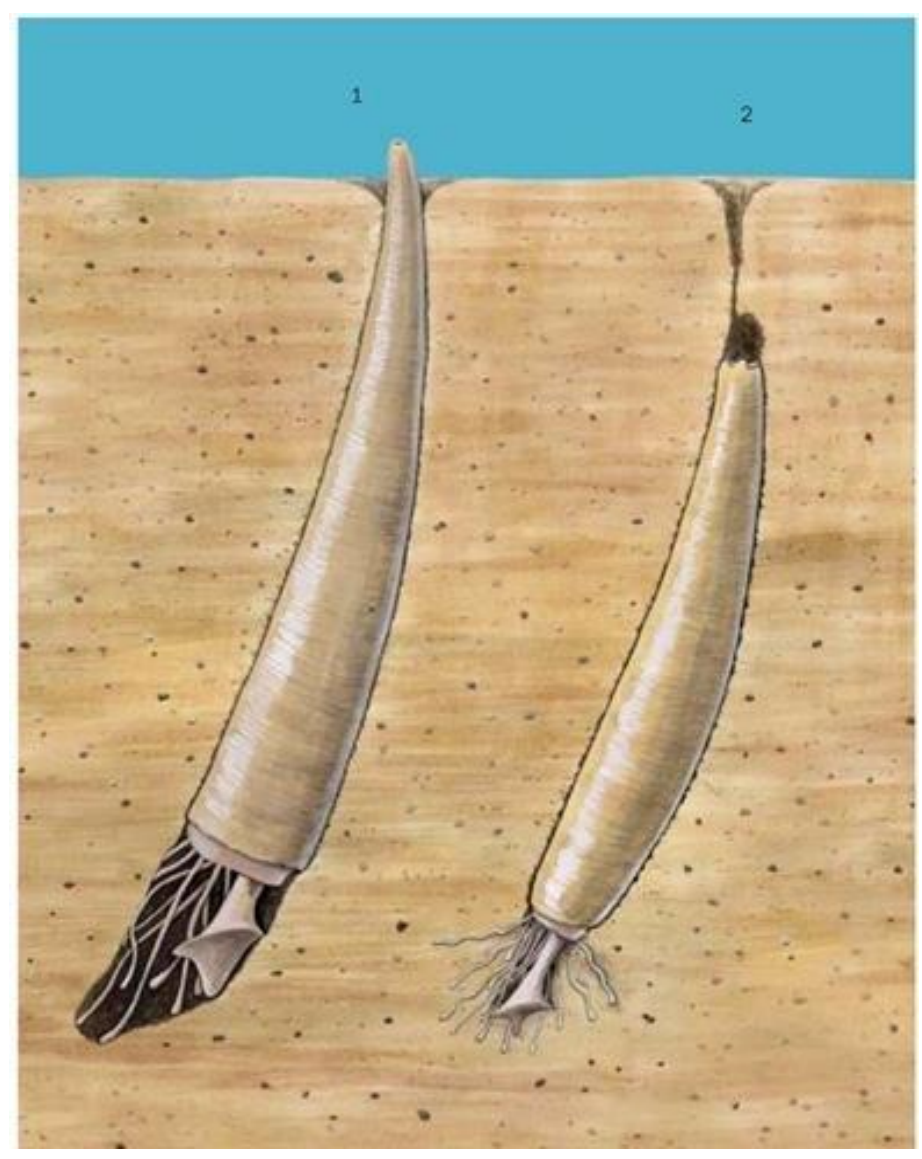

Gambar 2. Habitat Dentalium sp. 


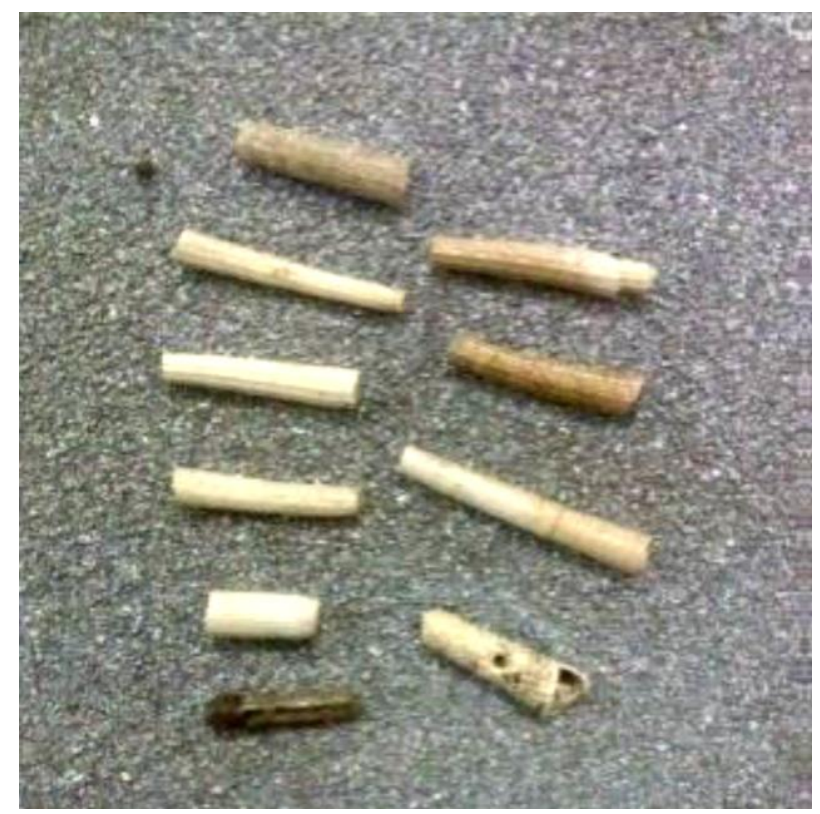

Gambar 3. Dentalium elephantinum (Suriadi, 2018).

Dentalium elephantinum merupakan jenis moluska yang membujur dan memiliki sembilan garis di punggung, memiliki warna yang menjilid seperti warna hijau lebih gelap di ujung bagian luar dan warna putih di bibir. Dentalium elephantinum ini hidup di air asin dan tersebar di Indo Pasifik (Oliver, 2004). Dalam penelitian Tenjing et al. (2018), di perairan India juga ditemukan Dentaliidae jenis Pictodentalium vernedei.

Genus Siphonodentalium terdiri dari 20 spesies. Sekitar 1/3 dari genus ini terdapat di air dangkal, sebagian besar di perairan boreal dan subboreal, 1/3 lainnya terdapat di abisal. Distribusi genus sangat sulit diketahui karena sebagian besar spesies yang diketahui dan dicatat berasal dari satu atau beberapa lokasi cangkang kosong (Knudsen, 1964). Genus Striocadulus terdiri dari spesies yang hidup di perairan cukup dalam di lautan tropis ditandai dengan cangkang melengkung berukuran sedang hingga besar. Striocadulus albicomatus terdapat di pantai barat Amerika Utara dan Tengah pada kedalaman 41-730 m; $S$. ludbrooki tersebar di Samudra Hindia utara pada kedalaman 528-732 m; S. pulcherrimus telah ditemukan dari Indonesia pada kedalaman 530-694 m, dan S. sagei dari Filipina dan Indonesia pada kedalaman 640-800 m. Striocadulus sagei, spesies terbesar dalam ordo Gadilida, ditemukan di Indonesia dan Filipina, panjangnya mencapai $43 \mathrm{~mm}$, cangkang bagian atas lebar dan sedikit terkompresi secara dorsoventral, dengan dua lobus lateral yang lebar (Scarabino, 1995). Informasi terperinci mengenai ciri cangkang S. pulcherrimus dari Indonesia tidak tersedia. Penelitian Knudsen (1964) dalam Ekspedisi Galathea di Palung Sunda pada kedalaman 6.900-7.000 m menemukan spesimen tunggal Siphonodentalium yang ditampilkan pada Gambar 4. Ini mengarah ke "Scaphopoda" atau "Siphonodentalium sp." sesuai Bruun (1957), Wolff (1960) dan Clarke (1962). Adanya bagian lunak membuktikan bahwa spesies ini benar-benar hidup di kedalaman. Beljaev \& Vikogradova (1961) menemukan enam spesimen Siphonodentalium sp. dari Palung Jawa (Sunda) pada kedalaman 6820-6850 m. 


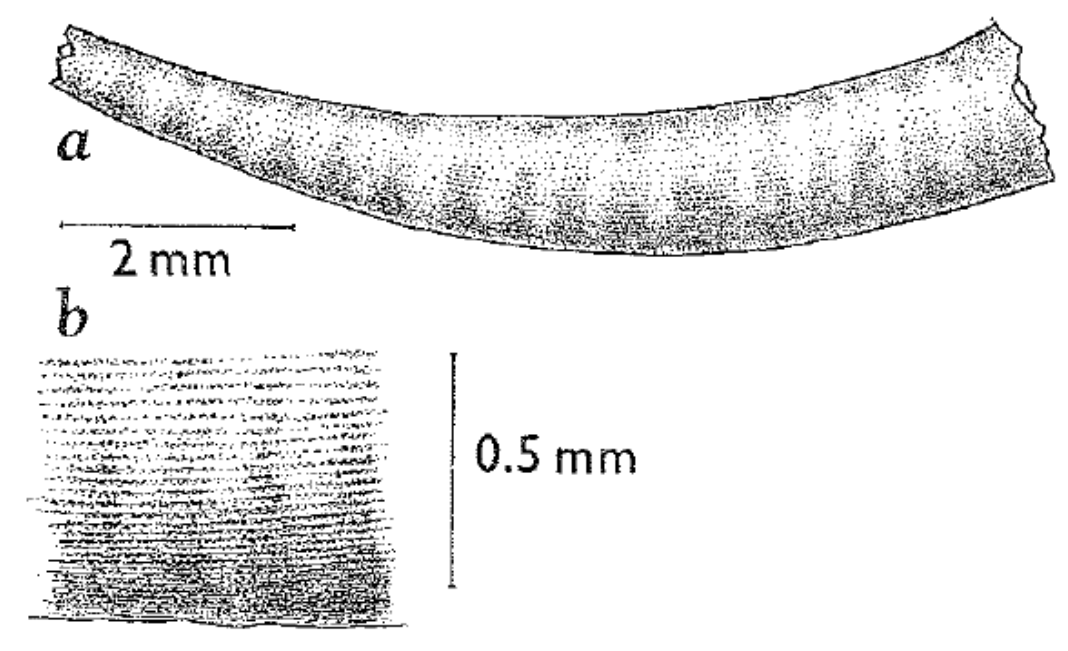

Gambar 4. Siphonodentalium galatheae; a. penampakan bagian cangkang;

b. detail permukaan cangkang.

\section{f. Makanan dan Kebiasaan Makan}

Makanan Scaphopoda umumnya terdiri dari berbagai organisme uniseluler (bersel tunggal) dan larva mikroskopis invertebrata kecil. Sebagian besar Scaphopoda mengkonsumsi foraminifer (Dinamani, 1964; Reynolds, 2002). Duff (1975) meneliti korelasi negatif antara kelimpahan Scaphopoda dan foraminifer di daerah Oxford. Pola serupa diamati oleh Kaim (2001) dalam lempung Valanginian dari Polandia. Dell (1957) menemukan mulut Dentaliurn zelandicum dipenuhi dengan Foraminifera, dan Morton (1959) dalam penelitiannya fokus mengenai makanan Dentalium entalir juga menemukan hal yang sama. Pada penelitian Gudmundsson et al. (2003) juga menemukan kantung bukal (daerah mulut) dari spesies Scaphopoda mengandung foraminifer, yang sesuai dengan penelitianpenelitian sebelumnya tentang Scaphopoda air dangkal dan dalam (Bilyard, 1974; Poon, 1987; Shimek, 1990; Langer et al., 1995). Makanan Scaphopoda selain foraminifer adalah organic spherical objects (OSO) atau benda bulat organik, krustasea harpacticoid, alga kecil, dan partikel mineral (Gudmundsson et al., 2003; Ozturk, 2011).

Scaphopoda yang berbeda memakan spesies makanan berbeda, yang mungkin disebabkan oleh beberapa faktor. Ketersediaan makanan dapat memengaruhi variasi ukuran tubuh organisme dan menjadi penyebab perbedaan tingkat pertumbuhan (Ibrahim et al., 2017). Spesies Scaphopoda yang lebih besar dapat memakan spesies foraminifer besar dan kecil, Scaphopoda yang lebih besar memakan lebih banyak makanan daripada Scaphopoda yang lebih kecil (Gudmundsson et al., 2003). Struktur anatomi dari Scaphopoda menentukan batas foraminifera yang mampu ditelan. Ukuran anterior cangkang, yang memanjang ke mulut menentukan batas kisaran ukuran mangsa yang dapat ditelan Scaphopoda. Ukuran diameter makanan Scaphopoda berbeda-beda, pada umumnya semakin besar ukuran mangsa maka semakin besar spesies Scaphopoda yang memakannya (Gudmundsson et al., 2003). 


\section{PENUTUP}

Scaphopoda merupakan salah satu kelas dalam filum Moluska yang belum banyak dikenal. Scaphopoda hidup di perairan laut dalam dan tidak dapat dikoleksi dengan mudah sehingga informasi mengenai biologi dan ekologi kelas ini masih sangat terbatas. Scaphopoda merupakan hewan bentik yang memiliki tubuh berukuran kecil dan cangkangnya meruncing. Kelas ini bersifat gonokoristik dan sebagian besar mengkonsumsi foraminifer. Pemahaman dan penyampaian informasi mengenai karakteristik dan beberapa aspek biologi Scaphopoda ini perlu dilakukan dengan harapan ilmu pengetahuan dapat terus dikembangkan dan dapat menggali potensi yang ada pada Scaphopoda agar kelestarian dan keberadaan Scaphopoda dapat tetap lestari dan berkelanjutan.

\section{DAFTAR PUSTAKA}

Barnes, R. (1987). Invertebrate Zoology. Orlando, Florida: Dryden Press.

Beljaev, G. M., \& Vinogradova, N. G. (1961). An Investigation of the Java Trench Deep-Sea Bottom Fauna. Okeanologiya, 1, 125-132.

Bilyard, G.R. (1974). The feeding habits and ecology of Dentalium entale stimpsoni Henderson. Veliger, 17, 126-138.

Brusca R., \& Brusca, G. (2003). Invertebrates. Sunderland, Massachusetts: Sinauer Associates, Inc.

Bruun, A. F. (1957). Deep sea and abyssal depths. In: treatise on marine ecology and paleoecology, Geal. Soc. Amer. Mem., 67(1), 641-672.

Clarke, A.H. (1962). Annotated list and bibliography of the abyssal marine molluscs of the world. Bull. Nat. Mus. Can, 181, 1-114.

Dell, R.K. (1957). A Revision of the recent Scapophod Mollusca of New Zealand. Trans. Roy. Soc. N.Z, 83, 561-576.

Dinamani, P. (1964). Feeding in Dentalium conspicuum. Proceedings of the Malacological Society of London, 36, 1-5.

Duff, K.L. (1975). Palaeoecology of a bituminous shale - the Lower Oxford Clay of central England. Palaeontology, 18, 443-482.

Encyclopedia. (2019). Scaphopoda (Tusk Shells). Retrieved from https://www.encyclopedia.com/env ironment/encyclopedias-almanacstranscripts-and-maps/scaphopodatusk-shells

Goedert, J. L. \& Squires, R. L. (1990). Eocene deep-sea communities in localized limestones formed by subduction-related methane seeps, southwestern Washington. Geology, 18, 1182-1185.

Gudmundsson, G., Engelstad, K., Steiner, G., Svavarsson, J. (2003). Diets of four deep-water scaphopod species (Mollusca) in the North Atlantic and the Nordic Seas. Marine Biology, 142, 1103-1112.

Grzimek, B., Schlager, N., \& Olendorf, D. (2003). Grzimek's Animal Life Encyclopaedia. Thomson Gale.

Ibrahim, P. S., Setyobudiandi, I., \& Sulistiono. (2016). Biologi reproduksi ikan selar kuning (Selaroides leptolepis Cuvier, 1833)di perairan Selat Sunda. Prosiding Seminar Nasional Ikan ke 9(Vol. 2, 613-621).

Ibrahim, P. S., Setyobudiandi, I., \& Sulistiono. (2017). Hubungan 
panjang bobot dan faktor kondisi ikan selar kuning selaroides leptolepis di perairan Selat Sunda. Jurnal Ilmu dan Teknologi Kelautan Tropis, 9(2), 577-584.

Kaim, A. (2012). Faunal dynamics of bivalves and scaphopods in the Bathonian (Middle Jurassic) orebearing clays at Gnaszyn, KrakowSilesia Homocline, Poland. Acta Geologica Polonica, 62(3), 381395.

Kaim, A. (2001). Faunal dynamics of juvenile gastropods and associated organisms across the Valanginian transgressionregression cycle in central Poland. Cretaceous Research, 22, 333-351.

Kozloff, E. N. (1996). Marine Invertebrates of the Pacific Northwest. 2nd. Seattle: University of Washington Press.

Morton, J. E. (1959). The Habits and Feeding Organs of Dentaliurn entalis. J. Mar. biol. Ass. U.K, 38, 225-238.

Romimohtarto, K., \& Juwana, S. (2007). Biologi Laut: Ilmu Pengetahuan tentang Biota Laut. Edisi Revisi. Cet. III; Jakarta: Djambatan.

Kurzawska, A., Bar-Yosef Mayer, D. E., Mienis, H. K. (2013). Scaphopod Shells in the Natufian Culture, In: Bar-Yosef O, Valla FR (Eds.), Natufian Foragers in the Levant: Terminal Pleistocene Social Changes in Western Asia, Archaeological Series 19. International Monographs in Prehistory, Ann Arbor, pp. 611-621.

Knudsen, J. (1964). Scaphopoda and Gastropoda from depths exceeding 6000 meters. Galathea Report 7:125-136., available online at http://www.zmuc.dk/inverweb/g alathea/Pdf_filer/Volume_07/galat hea-vol.07-pp_125-136.pdf. page(s): 127-129.

Langer, M. R., Lipps, J. H., Moreno, G. (1995). Predation on Foraminifera by the dentaliid deep-sea scaphopod Fissidentalium megathyris. DeepSea Res, I 42, 849-857.

Oliver, A. P. H. (2004). Philip's Guide to Seashells of The World. Buffalo (NY), Firefly Books. Octopus publishing, London.

Ozturk, B. (2011). Scaphopod species (Mollusca) of the Turkish Levantine and Aegean seas. Turkish Journal of Zoology. 35(2), 199-211.

Palmer, C. P., \& Steiner, G. (1998). Class Scaphopoda. Introduction. In: P. L. Beesley et al. (Eds), Mollusca: The Southern Synthesis. Fauna of Australia, 5, 431-438. CSIRO Publishing, Melbourne.

Poon, P. A. (1987). The diet and feeding behavior of Cadulus tolmiei Dall, 1897 (Scaphopoda, Siphonodentalioida). Nautilus, 101, 88-92.

Poppe, G. T., \& Goto, Y. (1993). European Seashells. Vol. 2: Scaphopoda, Bivalvia, Cephalopoda. Christa Hemmen, Wiesbaden, 222 pp.

Reynolds, P. D. (2002). The Scaphopoda. Advances in Marine Biology, 42, 137-236.

Scarabino, V. (1986). Nuevos taxa abisales de la clase Scaphopoda (Mollusca). Com. Zool. Mus. Hist. Nat. Montevideo, 11(155), 1-19.

Scarabino, V. (1994). Aproximación al número de especies de Scaphopoda actuales. Com. Soc. Malac. Uruguay 7, 357-361.

Scarabino, V. (1995). Scaphopoda of the tropical Pacific and Indian Oceans, 
with description of 3 new genera and 42 species. 654 p. In: Bouchet, P. (Ed.), Résultats des Campagnes MUSORSTOM. Mém. Mus. nat. Hist. natur., 167(14), 189-379.

Shimek, R. L. (1990). Diet and habitat utilization in a northeastern Pacific Ocean scaphopod assemblage. Am Malacol Bull, 7, 147-169.

Simone, L. R. L. (2009). Comparative morphology among representatives of main taxa of Scaphopoda and basal protobranch Bivalvia (Mollusca). Papéis Avulsos de Zoologia, 49(32).

Souza, L. S., Araújo, I. C. V., \& Caetano, C. H. S. (2013). A commented list of Scaphopoda (Mollusca) found along the Brazilian coast, with two new synonymies in the genus Gadila Gray, 1847. Biota Neotrop, 13(2).

Steiner, G., \& Dreyer, H. (2002). Molecular phylogeny of Scaphopoda (Mollusca) inferred from 18S rDNA sequences: support for a Scaphopoda-Cephalopoda clade. Zoologica Scripta, 32, 343356.
Steiner, G., \& Kabat, A. R. (2004). Catalogue of species-group names of Recent and fossil Scaphopoda (Mollusca). Zoosystema, 26(4), 549- 726.

Steiner, G. (1992). Phylogeny and Classification of Scaphopoda. Journal of Molluscan Studies, 58,385-400. Retrieved from http://mollus.oxfordjournals.org/

Surbakti, K., \& Ririmasse, M. N. R. (2016). Karakteristik dan Habitasi Moluska di Situs Hatusua Seram Bagian Barat Maluku Indonesia. Kapata Arkeologi 12(1), 91-102.

Suriadi, A. (2018). Temuan Sejarah di Desa Sako Kecamatan Rambutan sebagai Media Pembelajaran Sejarah Lokal. Prosiding Seminar Nasional 21 Universitas PGRI Palembang. ISBN 978-602-52451-0-7.

Wignall, P. B. (1990). Benthic palaeoecology of the late Jurassic Kimmeridge Clay of England. Special Papers in Palaeontology, 43, 1-74.

Wolff, T. (1960). The hadal community, an introduction. Deep-Sea Res., 6, 95124. 